\title{
Evaluation of Two Different Biomaterials Effect on Immediate Implant Stability and Bone Changes, a Randomized Parallel Group Clinical Trial
}

\author{
Gökhan Gürses ${ }^{1}$, Alparslan Esen ${ }^{1}$ \\ ${ }^{1}$ Necmettin Erbakan University, Dentistry Faculty, Department of Oral and Maxillofacial Surgery, Konya, Turkey
}

\begin{abstract}
How to rehabilitate the buccal gap of immediate implants is a point that confuses dentists. In this study, we aimed to compare the effect of the plasma rich fibrin $(P R F)$ and deproteinized bovine bone mineral(DBBM) on immediate implants which have gaps wider than $2 \mathrm{~mm}$ in terms of stability and crestal bone change. The total number of volunteers in our study is 15. All participants have an indication of extraction on tooth which has two adjacent teeth in the maxillar anterior or premolar region and rehabilitated with immediate implants. All individuals were divided into three groups as DBBM, PRF and Control by envelope method. Stability measurements was performed separately as mesiodistal(MD) and buccolingual(BP) at 0 and 120th day. CBCTs were taken pre-op and post-op 9th month. There was no statistically significant difference between the three groups in terms of mesial/distal and horizontal crest losses, T1-TO MD and BP changes. The use of PRF or DBBM in the buccal gap can contribute to the stability and prevents vertical and horizontal bone losses.
\end{abstract}

Keywords: buccal gap, bone loss, immediate implant, resonance frequency analysis

\section{Introduction}

Immediate implant protocol was introduced by Schulte in 1978 to overcome the disadvantages of conventional implant protocol such as time loss and bone resorption[1]. Since then, many studies have been conducted on immediate implants which mention other advantages including protecting alveolar anatomy[2] psychosocial benefits, and cost-effectiveness[3].

Nowadays, immediate implant application is widely used. The buccal gap left after the implant placement is an important point that confuses clinicians. To increase the success rate, dentists always seek to fill the gap with a biomaterial that they think improves and accelerates the bone healing. The researchers tried various materials and techniques such as deproteinized bovine bone mineral (DBBM), demineralized freeze-dried bone allograft (DFDBA)[4] guided bone regeneration (GBR)[5] plateletrich plasma (PRP)[6] and platelet-rich fibrin (PRF)[2].

PRF is a blood product which contains factors that associate soft and hard tissue healing[7]. There are studies reporting that the use of PRF in intra-bone defects contributes to a rapid recovery and improved bone formation $[8,9]$. But some long term studies indicates that PRF could not maintain its superiority to next periods and no significant differences between PRF+ and PRF- groups in terms of implant stability or crestal bone dimensional change[2,9].

GBR is a regenerative method based on the placement of a barrier membrane on the defect site. The function of membrane is to create a space for migration of guided tissue. By this way, the formation of the needed tissue could be observed. The membranes used for this purpose are typically classified as resorbable and non-resorbable membranes. Each type has its own indications, advantages and disadvantages [10].
Histological and clinical studies have reported that gaps with less than $2 \mathrm{~mm}$. could fill with bone spontaneously without any extra material or guided bone regeneration (GBR) procedures[11]. In cases of buccal gap wider than $2 \mathrm{~mm}$, it is not clear whether using graft/membrane alone or combination will lead the most satisfactory results [12]. The limited number of published studies and the comparison of different dental regions in the same study make it difficult to form a systematic review or meta-analysis.

The aim of this study is the comparison of DBMM and PRF with the control group in terms of stability and crestal bone loss on immediate implants which has buccal gap wider than $2 \mathrm{~mm}$. The null hypothesis of this study was that immediate implants which augmented with DBMM or PRF, have not enhanced osteointegration or radiographic outcomes.

\section{Methods}

This research was designed as a prospective randomized and parallel group clinical trial and conducted on 15 volunteers. We have calculated the sample size before the study. But due to the budget allocated to our study, we could not reach this number. This study followed the Declaration of Helsinki on medical protocol and ethics and the regional Ethical Review Board of Dentistry Faculty of Necmettin Erbakan University approved the study (Document Number: 2017-01). Patients who have an extraction indication on only one single rooted tooth in maxilla anterior and premolar region which have two periodontally healthy adjacent teeth were selected for the study. Exclusion criteria were patient with any systemic disease, dehiscence or fenestration in buccal socket wall before or after extraction, smoking and buccal gap less than $2 \mathrm{~mm}$ after implant placement. All interventions was operated at Necmettin Erbakan University, Dentistry Faculty. 


\section{International Journal of Science and Research (IJSR) \\ ISSN: 2319-7064}

Scientific Journal Impact Factor (2018): 7.426

Informed consents were obtained from all participants. Patients were randomly assigned to three different groups, including DBMM, PRF and control by envelope method. In the graft and PRF group, the relevant materials were placed in the buccal gap only. In the control group, no material was used.

Operator $1(\mathrm{O} 1)$ performed all surgeries and Operator $2(\mathrm{O} 2)$ executed all measurement including implant stability and radiographical. $\mathrm{O} 2$ was blinded to patients which group they relate. Participants were blinded to groups which they belong to.

This study has been registered for clinical trial on clinicaltrial.gov; registration number: NCT03501199.

\section{Surgical Procedure}

All surgeries performed by same operator. We use $\% 4$ articaine, 1:200.000 adrenaline as the anesthetic solution for infiltration anesthesia. Tooth was carefully extracted by using periotoms and forceps. The buccal socket wall was examined for fracture, fenestration or dehiscence. The implant osteotomy was done by subsequent drilling in accordance with the recommendations of the manufacturer (Bego Implants). The osteotomies were standardized (4.1x13 $\mathrm{mm}$. in canines, $3.75 \times 11.5$ in the other teeth). Top of the implant was placed $1 \mathrm{~mm}$ below the crestal bone level.

The buccal gap (space between the implant shoulder and buccal socket wall) was measured and the patient was excluded if the gap was less than $2 \mathrm{~mm}$ (Figure 1). Smartpegs were attached to implants and T0 implant stability quotients (ISQ) were measured buccopalatinally (BP) and mesiodistally (MD) by Osstell ISQ device. ISQs were recorded separately as $\mathrm{MD}$ and $\mathrm{BP}$.

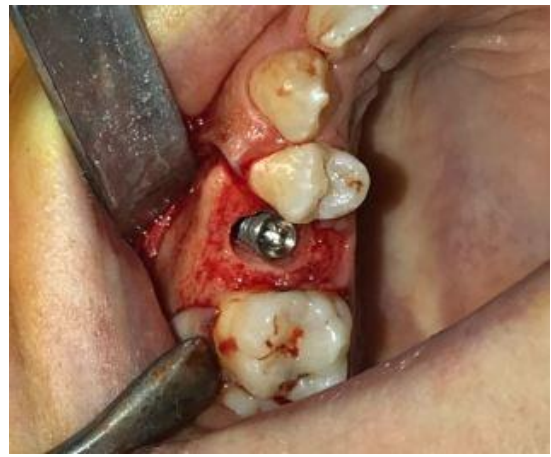

Figure 1: The buccal gap left after immediate implant placement

PRF was prepared in accordance with Choukroun's protocol [13] during surgery. PRF and DBMM (BegoOss, Germany) were placed in the buccal gap of the patients in the related groups. In all group, resorbable collagen membrane was used on the socket after implant placement (Figure 2). Waterproof closure was provided with 4-0 polyglactin suture. We prescribe antibiotics (500 mg. amoxicillin+125 $\mathrm{mg}$. clavulanic acid;2x1), analgesics (25 mg. dexketoprofen;2x1) and mouthwash $(0,12 \%$ chlorhexidine gluconate; $3 \times 1)$ for 5 days. The sutures were removed on the 7 th day. There was no complication about tissue healing in any participant.

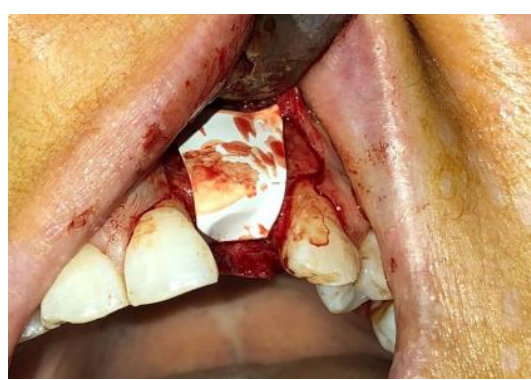

Figure 2: The placement of resorbable collagen membrane on the whole socket

T1 ISQ values were measured on 120th day by using the same method as T0 values. In the same surgery, gingival formers were placed and crowns were fixed within two weeks.

\section{Radiological Measurements}

Cone beam computed tomography (CBCT) was taken before surgery and after post-op 9. month. Pre-op buccal bone wall area calculation was made by using the field measurement feature of a tomography viewer on the mid-mesiodistal section of the tooth (Figure 3).

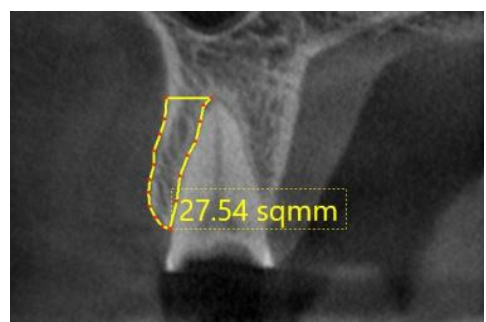

Figure 3: The measurement of the buccal bone wall area

Vertical bone loss in mesial/distal region was calculated. First, an imaginary line which passes through the enamelcement junction of the two adjacent teeth was created in preop and 9th-month post-op tomographies. Secondly, the distance between the top point of the interdental crest and the imaginary line was measured. The change of distance on these two tomographies accepted as vertical bone loss (Figure 4).
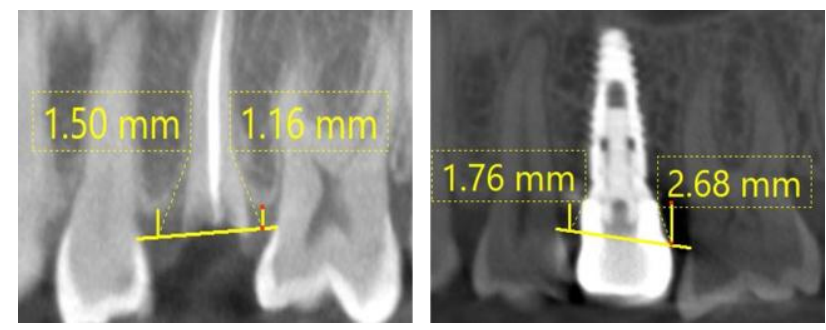

Figure 4: The measurement of vertical (mesial/distal) bone loss

Horizontal crest lost was calculated via the comparison of pre-op and post-op tomographies. In pre-op CBCT, horizontal crest wideness was measured on $4 \mathrm{~mm}$. below of enamel-cement junction. In post-op CBCT, measurement was made on $2 \mathrm{~mm}$. below the head of the implant. The difference between these two measurements was accepted as horizontal crest lost (Figure 5). 


\section{International Journal of Science and Research (IJSR)}

ISSN: 2319-7064

Scientific Journal Impact Factor (2018): 7.426
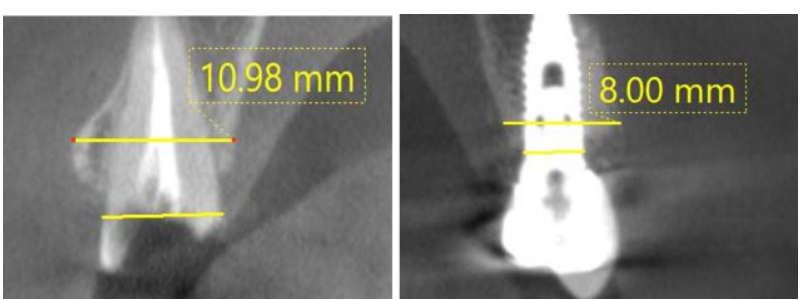

Figure 5: The measurement of horizontal crest loss

\section{Statistical Analysis}

We use SigmaPlot 12.5 software for statistical analysis. Shapiro Wilk test was used to find out the data fit the normal distribution or not. The dependent student t-test was applied for intra-group comparisons. One-way ANOVA test was used if the samples fit the normal distribution if not the Kruskal-Wallis test was applied. $p<0.05$ was accepted as the level of statistical significance.

\section{Results}

This study conducted between March 2018 to March 2019. The total number of volunteers is 15 which consist of two male (one in PRF, one in control group) and thirteen female. The mean age was $39.1( \pm 10)$ (range: $24-56)$. There were 3 canines, 5 laterals and 7 second premolars in the study. There was no excluded participant in the study. All of the patients participated in the 9th month controls planned as the follow up period.

No statistically significant difference was found between the groups according to their age $(\mathrm{p}=0,238)$, buccal bone wall area $(p=0,814)$, T0-MD ISQ values $(p=0,064)$, T0-BP ISQ values $(p=0,910), T 1-M D$ ISQ values $(p=0,734), T 1-B P$ ISQ values $(\mathrm{p}=0,543)$.

The mean MD and BP ISQ differences (T1-T0) were shown in Table 1. There was no significant difference between the groups in terms of MD or BP ISQ difference. The mean vertical (mesial-distal) and horizontal bone losses were shown in Table 2. Statistical analysis showed that no significant difference was found between groups in terms of vertical or horizontal bone losses.

Table 1: Mean MD and BP ISQ changes

\begin{tabular}{|c|c|c|}
\hline & $\begin{array}{c}\text { Mean MD } \\
\text { ISQ Difference (SD) }\end{array}$ & $\begin{array}{c}\text { Mean BP } \\
\text { ISQ Difference (SD) }\end{array}$ \\
\hline DBMM & $15,2( \pm 5,1)$ & $19,4( \pm 7,5)$ \\
\hline PRF & $10( \pm 8,1)$ & $13,8( \pm 7,7)$ \\
\hline Control & $7,6( \pm 5,8)$ & $11,4( \pm 8,4)$ \\
\hline p value & 0,212 & 0,323 \\
\hline
\end{tabular}

SD: Standard Deviation

As seen in this table, the highest ISQ difference occurred in the DBMM group. This is followed by the PRF and the Control group. But no statistically significant difference was found in the neither MD nor BP ISQ changes.
Table 2: Mean horizontal and vertical bone losses

\begin{tabular}{|c|c|c|c|}
\hline & $\begin{array}{c}\text { Mean mesial } \\
\text { bone loss (SD) }\end{array}$ & $\begin{array}{c}\text { Mean distal } \\
\text { bone loss (SD) }\end{array}$ & $\begin{array}{c}\text { Mean horizontal } \\
\text { bone loss (SD) }\end{array}$ \\
\hline DBMM & $0,88( \pm 0,38)$ & $0,71( \pm 0,37)$ & $0,84( \pm 0,16)$ \\
\hline PRF & $1,68( \pm 0,51)$ & $1,46( \pm 0,65)$ & $1,52( \pm 0,26)$ \\
\hline Control & $1,85( \pm 0,37)$ & $1,62( \pm 0,29)$ & $2,02( \pm 1,16)$ \\
\hline p value & 0,455 & 0,743 & 0,367 \\
\hline
\end{tabular}

SD: Standart Deviation

As seen in this table, the highest bone loss occurred in the Control Group. This is followed by the PRF and the DBMM Group. But no statistically significant difference was found in the neither vertical nor horizontal bone loss.

A correlation of 0.28 ( $\mathrm{p}$ value:0,3) coefficients was found between the buccal wall bone area and the ISQ differences. However, it was not statistically significant.

\section{Discussion}

The concept of the immediate implant, introduced by Schulte in 1978[1], has had a great impact on dentistry. This introduction has brought many advantages than conventional protocol such as shorter treatment time, cost-effective and psychosocial benefits[13]. But the buccal gap has always been a question mark for clinicians. In the Consensus conference held by ITI in 2014, it is clearly stated that the gaps with less than $2 \mathrm{~mm}$. could show success in terms of aesthetical and clinical outcomes without any extra material[11]. However, it is not clear that which method or material could be used in larger gaps for best outcomes. In the present study, we tried to answer this question and compared PRF and DBMM with the control group to find out the best outcomes.

We included only maxilla anterior and premolar teeth in our study. These teeth are known as aesthetic region, patients generally desire to rehabilitate these teeth with immediate implant for short treatment time. Also these regions have similar type of bone. At the same time, we tried to standardize the implant sizes and tried to minimize the differences in healing and stability values.

The RFA was used for measure the implant stability at T0 and $\mathrm{T} 1$, which is non-invasive and repeatable and better predictability than other methods[14]. Our study results show that a significant stability increase in all groups after 4 months $(p<0,05)$. But the significant difference was found between all groups in neither MD nor BP T1-T0 ISQ values.

Earlier research reported that primer ISQ values below 44 are related to low success rate[15]. In our study, the primary ISQ values ranged from 43 to 69 . The lowest primer value was measured as 43 in one implant of graft group. It increased to 75 at the end of the 4th month. All implant has higher ISQ values than the threshold of low stability according to the ISQ scale which was prepared by Osstell manufacturer at the time of T1 measurement.

As far as we know, there is no study in the literature measuring the buccal socket wall area or volume. We thought that the thickness of the buccal bone might be

\section{Volume 8 Issue 9, September 2019 www.ijsr.net}




\section{International Journal of Science and Research (IJSR) \\ ISSN: 2319-7064}

Scientific Journal Impact Factor (2018): 7.426

related to the filling of the buccal gap with bone and the improvement of the stability. The data of our study shows that there is a correlation between wall area and BP ISQ difference. But this correlation is quite low to make a generalization (correlation value:0,28, $\mathrm{p}$ value:0,3).

DBBM is an effective graft material to regenerate adequate new bone[16]. In studies using DBBM, they reported that buccal hard tissue was less resorbed and the width of the alveolar ridge was maintained[17,18]. In our study, we could find any significant difference among the groups in term of bone loss. Some researchers suggesting that spaces less than $2 \mathrm{~mm}$ are not sufficient for the organization of blood clots to form new woven bone[19,20]. This situation might appear due to all implant in our study have wider gap than $2 \mathrm{~mm}$.

The multicenter study conducted by Mastrangelo et al.[21], compared DBBM plus membrane with no biomaterial group. They stated that there was no statistically difference in term of crestal bone changes or probing depth. According to them, extra biomaterials could improve only esthetic outcomes and patient satisfaction.

Sanz et al.[17] placed DBBM in the buccal gap of immediate implants. The gaps more than $2 \mathrm{~mm}$ were evaluated separately, in this study. They reported, there was no significant differences between the control and graft group in crestal dimensional change. Our results are similar to last two aforementioned studies.

We used PRF as a sole filling material. When PRF is placed between the implant and the buccal socket wall, it has been shown to assist angiogenesis and hemostasis, and release growth factors[22]. The studies which used PRF as a graft material reported enhanced bone formation[23,24]. Becker et al. and Anitua et al. noted increased bone-implant contact when used PRF[5,25].

In a study conducted on 20 patient of Öncü and Alaaddinoglu [26], two conventional implants which one of them coated with PRF were placed. They reported significant differences for stability at the end of the first and fourth week. But we could not find this difference in our study. The reason may be lack of follow-up in their study. Because PRF can enhance the stability at the initial healing process by high alkaline phosphatase activity before dissolution in 10-14 days[27]. In another study on immediate implants of Öncü and Erbeyoğlu stated that significant difference was found between PRF+ and control group based on implant stability at the first and fourth week. But there was no significant differences in terms of crestal resorption at the end of first year[9].

Diana et al.[2] placed PRF in the buccal gap in a study of 20 immediate implants which 10 of them in the control group. The implants were applied to both maxilla and mandible. They noted that there was no significant differences between groups in terms of stability and bone resorption at 1-year follow-up. They also noted that the PRF group has relatively higher ISQ values and relatively lower crestal bone loss than the control group. Our results are similar to this study.
In our study, we used a membrane to protect the buccal gap in the control group and to avoid fibro-osseous healing. The results of our study showed that in cases where more than 2 mm gap was formed, membrane application induced bone formation, improved osteointegration and prevented crestal bone resorption.

The total success rate of our study at the end of 9 months is $100 \%$. These rates are higher compared to other studies $[2,28]$. The use of membranes in all groups, no early loading and primary closure may have been effective in this difference.

\section{Conclusion}

In the limitation of this study; although no statistical difference was found between the groups, in cases where the buccal gap is more than $2 \mathrm{~mm}$, the use of PRF or DBBM in the buccal gap can contributes to stability and prevents vertical and horizontal bone losses. The use of at least the membrane enhance the stability and affect positively to bone formation in cases which gaps wider than $2 \mathrm{~mm}$.

\section{Acknowledgments}

All expenses of this research was granted by Projects of Scientific Research Department, Necmettin Erbakan University.

\section{References}

[1] Schulte W, Kleineikenscheidt H, Lindner K, Schareyka R: [The Tübingen immediate implant in clinical studies]. Dtsch Zahnarztl Z 33: 348, 1978.

[2] Diana C, Mohanty S, Chaudhary Z, Kumari S, Dabas J, Bodh R: Does platelet-rich fibrin have a role in osseointegration of immediate implants? A randomized, single-blind, controlled clinical trial. Int $\mathrm{J}$ Oral Maxillofac Surg 47: 1178, 2018.

[3] Werbitt MJ, Goldberg PV: The immediate implant: bone preservation and bone regeneration. Int $\mathbf{J}$ Periodontics Restorative Dent 12: 206, 1992.

[4] Gher ME, Quintero G, Assad D, Monaco E, Richardson AC: Bone Grafting and Guided Bone Regeneration for Immediate Dental Implants in Humans. J Periodontol 65: 881, 1994.

[5] Becker W, Lynch SE, Lekholm U, Becker BE, Caffesse R, Donath K, Sanchez R: A Comparison of ePTFE Membranes Alone or in Combination with PlateletDerived Growth Factors and Insulin-Like Growth Factor-I or Demineralized Freeze-Dried Bone in Promoting Bone Formation Around Immediate Extraction Socket Implants. J Periodontol 63: 929, 1992.

[6] You T-M, Choi B-H, Zhu S-J, Jung J-H, Lee S-H, Huh $\mathrm{J}-\mathrm{Y}$, Lee H-J, Li J: Platelet-enriched fibrin glue and platelet-rich plasma in the repair of bone defects adjacent to titanium dental implants. Int $\mathbf{J}$ Oral Maxillofac Implants 22: 417, 2007.

[7] Dohan DM, Choukroun J, Diss A, Dohan SL, Dohan AJJ, Mouhyi J, Gogly B: Platelet-rich fibrin (PRF): a second-generation platelet concentrate. Part III: 


\section{International Journal of Science and Research (IJSR)}

ISSN: 2319-7064

Scientific Journal Impact Factor (2018): 7.426

leucocyte activation: a new feature for platelet concentrates? Oral Surg Oral Med Oral Pathol Oral Radiol Endod 101: e51, 2006.

[8] Anitua E, Andia I, Ardanza B, Nurden P, Nurden AT: Autologous platelets as a source of proteins for healing and tissue regeneration. Thromb Haemost 91: 4, 2004.

[9] Öncü E, Erbeyoğlu AA: Enhancement of Immediate Implant Stability and Recovery Using Platelet-Rich Fibrin. Int J Periodontics Restorative Dent 39: e58, 2019.

[10]El Helow K, El Askary AES: Regenerative barriers in immediate implant placement: a literature review. Implant Dent 17: 360, 2008.

[11] Morton D, Chen ST, Martin WC, Levine RA, Buser D: Consensus statements and recommended clinical procedures regarding optimizing esthetic outcomes in implant dentistry. Int J Oral Maxillofac Implants 29 Suppl: 216, 2014.

[12] AlKudmani H, AL Jasser R, Andreana S: Is Bone Graft or Guided Bone Regeneration Needed When Placing Immediate Dental Implants? A Systematic Review. Implant Dentistry 26: 936, 2017.

[13] Dohan DM, Choukroun J, Diss A, Dohan SL, Dohan AJJ, Mouhyi J, Gogly B: Platelet-rich fibrin (PRF): a second-generation platelet concentrate. Part I: technological concepts and evolution. Oral Surg Oral Med Oral Pathol Oral Radiol Endod 101: e37, 2006.

[14] Herrero-Climent M, Santos-Garcia R, Jaramillo-Santos R, Romero-Ruiz MM, Fernandez-Palacin A, LazaroCalvo P, Bullon P, Rios-Santos JV: Assessment of osstell isq's reliability for implant stability measurement: A cross-sectional clinical study. Medicina Oral Patología Oral y Cirugia Bucal: e877, 2013.

[15] Sennerby L, Meredith N: Implant stability measurements using resonance frequency analysis: biological and biomechanical aspects and clinical implications. Periodontol 2000 47: 51, 2008.

[16] Wessing B, Lettner S, Zechner W: Guided Bone Regeneration with Collagen Membranes and Particulate Graft Materials: A Systematic Review and MetaAnalysis. Int J Oral Maxillofac Implants 33: 87, 2018.

[17] Sanz M, Lindhe J, Alcaraz J, Sanz-Sanchez I, Cecchinato D: The effect of placing a bone replacement graft in the gap at immediately placed implants: a randomized clinical trial. Clin Oral Implants Res 28: 902, 2017.

[18] Araújo MG, Silva JCC da, Mendonça AF de, Lindhe J: Ridge alterations following grafting of fresh extraction sockets in man. A randomized clinical trial. Clinical Oral Implants Research 26: 407, 2015.

[19] Buser D, Chappuis V, Belser UC, Chen S: Implant placement post extraction in esthetic single tooth sites: when immediate, when early, when late? Periodontol 2000 73: 84, 2017.

[20] Araújo MG, Sukekava F, Wennström JL, Lindhe J: Tissue modeling following implant placement in fresh extraction sockets. Clin Oral Implants Res 17: 615, 2006.

[21] Mastrangelo F, Gastaldi G, Vinci R, Troiano G, Tettamanti L, Gherlone E, Lo Muzio L: Immediate Postextractive Implants With and Without Bone Graft: 3-year Follow-up Results From a Multicenter Controlled
Randomized Trial. Implant Dent 27: 638, 2018.

[22] He L, Lin Y, Hu X, Zhang Y, Wu H: A comparative study of platelet-rich fibrin (PRF) and platelet-rich plasma (PRP) on the effect of proliferation and differentiation of rat osteoblasts in vitro. Oral Surg Oral Med Oral Pathol Oral Radiol Endod 108: 707, 2009.

[23] Mazor Z, Horowitz RA, Del Corso M, Prasad HS, Rohrer MD, Dohan Ehrenfest DM: Sinus floor augmentation with simultaneous implant placement using Choukroun's platelet-rich fibrin as the sole grafting material: a radiologic and histologic study at 6 months. J Periodontol 80: 2056, 2009.

[24] Hoaglin DR, Lines GK: Prevention of Localized Osteitis in Mandibular Third-Molar Sites Using Platelet-Rich Fibrin. Int J Dent 2013: 1, 2013.

[25] Anitua E, Orive G, Pla R, Roman P, Serrano V, Andía I: The effects of PRGF on bone regeneration and on titanium implant osseointegration in goats: A histologic and histomorphometric study. J Biomed Mater Res A 91A: 158, 2009.

[26] Öncü E, Alaaddinoğlu EE: The effect of platelet-rich fibrin on implant stability. Int $\mathbf{J}$ Oral Maxillofac Implants 30: 578, 2015.

[27] Wang J, Wang L, Zhou Z, Lai H, Xu P, Liao L, Wei J: Biodegradable Polymer Membranes Applied in Guided Bone/Tissue Regeneration: A Review. Polymers 8: 115, 2016.

[28] Polizzi G, Grunder U, Goené R, Hatano N, Henry P, Jackson WJ, Kawamura K, Renouard F, Rosenberg R, Triplett G, Werbitt M, Lithner B: Immediate and Delayed Implant Placement Into Extraction Sockets: A 5-Year Report. Clinical Implant Dentistry and Related Research 2: 93, 2000.

Volume 8 Issue 9, September 2019

www.ijsr.net

Licensed Under Creative Commons Attribution CC BY 